\title{
El impacto diferenciado en las afectaciones a los derechos humanos de niñas y niños: una categoría de análisis propia desde una perspectiva de infancia The Differentiated Impact of Human Rights Violations on Girls and Boys: A New Category of Analysis from a Childhood Perspective
}

\author{
Luis González Placencia \\ Comisión de Derechos Humanos del Distrito Federal, México
}

Es doctor en ciencias penales por el Instituto Nacional de Ciencias Penales; es egresado magna cum laude aprobatur del Instituto Internacional de Sociología Jurídica, con sede en Oñati, España, donde obtuvo el Master in Law. Es también licenciado en psicología por la UNAM. Durante dos décadas y media ha combinado el servicio público con la academia, desempeñándose en diversos puestos en el Instituto Nacional de Ciencias Penales, la Comisión Nacional de Derechos Humanos, el Consejo de la Judicatura Federal, la Universidad Autónoma Metropolitana, UNICEF, las universidades estatales de Querétaro, Guanajuato, Campeche y Tlaxcala, así como en la Comisión de Derechos Humanos del Distrito Federal. En septiembre de 2009 la Asamblea Legislativa del Distrito Federal lo eligió por unanimidad para ejercer el cargo de Presidente de la Comisión de Derechos Humanos del Distrito Federal, cargo que desempeña hasta la fecha.

luis.gonzalez@cdhdf.org.mx

\section{Ricardo Ortega Soriano}

Centro de Investigación Aplicada en Derechos Humanos de la Comisión de Derechos Humanos del Distrito Federal, México

Es egresado de la Facultad de Derecho de la Universidad Nacional Autónoma de México, graduado con mención honorífica y Maestro en Derecho por la División de Estudios de Posgrado de la Facultad de Derecho de la UNAM, graduado también con mención honorífica. Candidato a Doctor en Derecho de la Facultad de Derecho de la UNAM así como de la Universidad Carlos III de Madrid. Actualmente se desempeña como Director Ejecutivo del Centro de Investigación Aplicada en Derechos Humanos de la Comisión de Derechos Humanos del Distrito Federal (CIADH-CDHDF).

ricardo.ortega@cdhdf.org.mx

\section{RESUMEN}

El artículo propone una perspectiva de infancia como categoría de análisis que permite identificar el impacto diferenciado de ciertas violaciones a los derechos de niñas y niños. Asimismo, reconoce que el análisis con perspectiva de infancia se encuentra fundado en la doctrina de la protección integral de los derechos de la infancia e incluye el reconocimiento de niñas y niños como sujetos de derechos; una visión amplia del principio de igualdad sustancial; $y$ la eficacia del principio del interés superior de la niña y el niño. Particularmente, el estudio analiza cómo el concepto general de plazo razonable no es suficiente para asegurar las

\section{SUMMARY}

The paper proposes a childhood perspective as a category of analysis capable of identifying the differentiated impact of certain violations to the rights of girls and boys. It also acknowledges that the analysis from a childhood perspective is based on the doctrine of the comprehensive protection of children's rights, and it encompasses: the recognition of girls and boys as rights-holders; a broad interpretation of the substantive equality principle; and a commentary on the effectiveness of the principle of the best interest of the child. In particular, the paper suggests that the general concept of 'reasonable time' is not enough to 
medidas especiales de protección de los derechos de niñas y niños, por lo que resulta necesaria la identificación de medidas reforzadas que eviten la generación de impactos agravados a sus derechos.

Palabras clave: derechos de las niñas y niños - infancia - interés superior de la niña y niño - plazo razonable. guarantee the special measures required for the protection of children's rights, so that it is crucial that reinforced measures are identified in order to prevent a further impact on their rights.

Key words: Rights of girls and boys - childhood best interest of the child - reasonable time.

\section{Introducción}

Durante los últimos años, el desarrollo de las perspectivas teóricas relacionadas con los derechos humanos ha tenido como uno de sus componentes esenciales el estudio del principio de igualdad sustancial ${ }^{1}$.

Desde luego, no es el propósito del presente artículo analizar el complejo desarrollo que ha experimentado esta noción de igualdad a la luz de las diversas perspectivas de análisis de los derechos humanos ${ }^{2}$. Este escrito surge producto de diversas reflexiones relacionadas con la necesidad de contar con un aparato teórico que permita asegurar una mayor protección de los derechos de niñas y niños a partir de un mejor entendimiento de la situación de vulnerabilidad y del principio de igualdad ${ }^{3}$.

En función de ello, el cometido que hemos trazado pasa por dos grandes consideraciones. La primera de ellas permitirá plasmar un bosquejo de aquellos elementos que configurarían un análisis con perspectiva de infancia para la comprensión de los derechos de niñas y niños; y, la segunda, entender la necesidad de evaluar un impacto diferenciado de las violaciones a sus derechos en relación con las afectaciones que sufren las personas adultas.

De alguna manera, hemos recuperado la esencia del planteamiento expuesto por la Corte Interamericana de Derechos Humanos (Corte IDH) en el caso del Penal Miguel Castro Castro aplicado a las afectaciones a los derechos humanos de las mujeres, y en donde se constató, al analizar los hechos y sus consecuencias, que los actos de violencia habían sido dirigidos específicamente a las mujeres $y$, por tanto, habían impactado de manera diferenciada en sus derechos humanos.

La constatación de los factores que genera dicha discriminación constituye uno de los aspectos fundamentales que permite trazar las bases del análisis o perspectiva de género. Sin embargo, dicha identificación también es un punto de partida para la construcción de conceptos y categorías de

1 De acuerdo con el profesor Luigi Ferrajoli, los derechos fundamentales constituirían la base de la igualdad jurídica. FERRAJOLI, Luigi. Derechos y Garantías. La Ley del más débil. Madrid: Trotta, 1999. p. 38.

2 Para una revisión histórica sobre la evolución del principio de igualdad formal hacia una comprensión amplia de la igualdad sustancial véase: SANTIAGO JUÁREZ, Mario. Igualdad y acciones afirmativas. México: Instituto de Investigaciones Jurídicas de la UNAM, Serie Doctrina Jurídica, No. 399, pp. 13-17.

3 Por ejemplo, han contribuido en este análisis el desarrollo del derecho antidiscriminatorio en los Estados Unidos, o bien, el análisis de la perspectiva de género en el marco ya sea de las luchas feministas por la igualdad o bien de quienes reivindican la existencia de sociedades plurales que no ejerzan discriminación hacia las personas en función de su orientación o identidad sexual. Desde luego, tales categorías podrían Ilevarnos al replanteamiento del modelo individualista del principio de igualdad que "no provee de suficientes herramientas para decidir en una gran cantidad de casos, en los que las diferencias de hecho entre las personas y, en particular, las diferencias que surgen a partir de un trato sistemáticamente excluyente o de sometimiento son relevantes para realizar tratos diferentes que no serían tolerados por esa visión individualista de la igualdad". SABA, Roberto. "(Des) igualdad estructural". En: ALEGRE, Marcelo y GARGARELLA, Roberto (Coords.). El Derecho a la lgualdad. Aportes para un constitucionalismo igualitario. Buenos Aires: Lexis Nexis, 2007, pp. 178 y 179. 
análisis que buscan revertir tales condiciones. Por ello, si partimos de la premisa de que niñas y niños se enfrentan a condiciones de discriminación estructural, ocasionadas por factores simbólicos y culturales que mantienen un ámbito de opresión en su contra, entonces podríamos reconocer la necesidad de considerar un aparato teórico que permita combatir tal situación ${ }^{4}$.

Así las cosas, el presente análisis establece a la luz de los criterios desarrollados por la Corte Interamericana en relación con los derechos de niñas y niños, aquellos elementos que permitirían la configuración de lo que llamaremos "perspectiva o enfoque de infancia". Posteriormente, y a partir de dicho enfoque, advertiremos cómo los más recientes criterios del referido tribunal han comenzado a identificar aspectos donde se generan impactos diferenciados en los derechos de niñas y niños. Particularmente analizaremos los derechos de los niños y niñas ante procedimientos judiciales en los casos Atala Riffo e Hijas vs. Chile; Fornerón e Hija vs. Argentina; y Furlán y familiares vs. Argentina.

Antes de continuar con este desarrollo, debe resaltarse que el establecimiento de una perspectiva de infancia no debe ser excluyente del reconocimiento de los diversos planos que conforman las identidades de las personas, y en donde es posible que las personas además de niñas o niños puedan vivir con discapacidad, auto adscribirse como personas indígenas, o vivir con alguna otra condición que genere alguna situación de riesgo o vulnerabilidad. Un enfoque de infancia será siempre comprensivo con la más amplia concepción del principio de igualdad.

Como podrá apreciarse con mayor amplitud a lo largo del presente estudio, el referido enfoque o perspectiva de infancia deberá -utilizando una expresión de Robert Alexy-irradiar el contenido del corpus juris internacional de protección de los derechos de niñas y niños ${ }^{5}$.

\section{Elementos para la construcción de un enfoque de derechos basado en la infancia}

La construcción de una categoría de análisis que permita identificar las condiciones de sometimiento y opresión que configuran situaciones de discriminación estructural y que representan obstáculos permanentes o sistemáticos para el pleno ejercicio de los derechos de niñas y niños se deberá considerar fundamental para poder revertir tales condiciones.

Desde esta perspectiva, los elementos que a continuación presentamos se ubican en la mira de los obstáculos expuestos, y pretenden configurar un punto de vista capaz de remontar las dificultades que enfrentan los derechos de la infancia.

La Convención sobre los Derechos del Niño (CDN) integra dos objetivos para una aproximación con perspectiva de infancia ${ }^{6}$. La primera de ellas parte de la necesidad de extender los derechos

4 De acuerdo con Roberto Saba, existirían dos visiones de la igualdad. Una más cercana al pensamiento liberal clásico de corte individualista, y otra de naturaleza estructural. Nuestro análisis se basa en una aproximación al tema que analizamos desde este último enfoque. Al respecto, "[d]e acuerdo con esta perspectiva [estructural] resulta relevante la incorporación de datos históricos y sociales que dé cuenta del fenómeno de sometimiento y exclusión sistemática a la que se encuentran sometidos amplios sectores de la sociedad". SABA, Roberto. "(Des)igualdad estructural", op. cit., p. 166.

5 La Corte Interamericana ha afirmado en diversas ocasiones que "este corpus juris debe servir para definir el contenido y los alcances de las obligaciones que ha asumido el Estado cuando se analizan los derechos de niños y niñas". Corte IDH. Caso Fornerón e hija vs. Argentina. Fondo, Reparaciones y Costas. Sentencia de 27 de abril de 2012. Serie C No. 242, párr. 44; Caso de los "Niños de la Calle" (Villagrán Morales y otros) vs. Guatemala. Fondo. Sentencia de 19 de noviembre de 1999. Serie C No. 63, párr. 194; y, Caso Gelman vs. Uruguay. Fondo y Reparaciones. Sentencia de 24 de febrero de 2011. Serie C No. 221, párr. 121.

6 Desde luego, la perspectiva de infancia debe ser entendida como un complemento, o en el marco de la doctrina de la protección integral de los derechos de niñas y niños, para ver más elementos respecto de la protección integral consultar 
que habitualmente son reconocidos a los adultos hacia niñas y niños, en una lógica de inclusión con la finalidad de evitar prácticas de exclusión y explotación 7 .

Una segunda aproximación permite reconocer que las y los niños se ubican en una situación de especial vulnerabilidad, por lo que requieren medidas específicas de protección. Este enfoque basado en el reconocimiento refiere que las y los niños no deben ser tratados bajo modelos a escala de los adultos, sino que deben ser considerados como sujetos plenos de derechos en atención de la situación en la que desarrolle sus potencialidades ${ }^{8}$.

Los dos principios expuestos constituyen la base para identificar aquellos elementos a partir de los cuales podría hablarse de un enfoque de infancia, y que podrían ser desglosados en los siguientes elementos, que serán abordados brevemente.

\subsection{Niñas y niños como sujetos de derechos: un enfoque basado en el reconocimiento del prin- cipio de autonomía progresiva}

La Corte Interamericana ha reiterado en diversas ocasiones que los niños y niñas además de ser titulares de los derechos establecidos en la Convención Americana, gozan de medidas especiales de protección que deben ser definidas según las circunstancias de cada caso concreto ${ }^{9}$. Al respecto, podría afirmarse que este reconocimiento implica adicionalmente considerarles como un sujeto social con participación activa, como una persona humana con todos sus derechos ${ }^{10}$.

Esta manera de concebir a niñas y niños debería entonces cancelar la imagen previa del "menor" como objeto de compasión y/o represión ${ }^{11}$, abriendo la discusión acerca de la ciudadanía en

LONDOÑO, Beatriz. "El Instituto Colombiano de Bienestar Familiar". En: Universidad de los Andes. Niñez y Conflicto armado: Desde la desmovilización hacia la garantía integral de derechos de infancia. Colombia: Universidad de los Andes, 2003.

7 "Its first objective is to extend the fundamental human rights recognised for adults to children. This may be seen for example in provisions regarding freedom of conscience, rights to privacy, rights to voice and participation, and civil liberties. The logic here is inclusion: to challenge unthinking assumptions of children's 'difference', and the age-based exclusionary and exploitative practices to which this can give rise". WHITE, Sara. "Being, becoming and relationship: conceptual challenges of a child rights approach in development", p. 2. [en línea] <http://peelearlyyears.com/pdf/ Being,\%20Becoming\%20and\%20Relationship-\%20Conceptual\%20Challenges $\% 20$ of $\% 20$ a $\% 20$ Child $\% 20$ Rights $\% 20$ Approach\%20in\%20Development.pdf> [consulta: 2 noviembre 2012].

8 "It thus identifies children as a priority group for special intervention, with regard for example to appropriate schooling and health care provision, and protection from economic and sexual exploitation and exposure to harmful work. The key issue here is recognition: that children should not simply be regarded as scale model adults, but taken on their own terms, as a set of development subjects requiring a distinctive and particular approach". Ídem.

9 Corte IDH. Caso Fornerón e hija, op. cit., p. 45; Caso Gelman, op. cit., párr. 121; y, Caso Atala Riffo y Niñas vs. Chile. Fondo, Reparaciones y Costas. Sentencia de 24 de febrero de 2012. Serie C No. 239, párr. 196. De igual manera, la Corte IDH ha sostenido que: el niño tiene derecho a vivir con su familia, la cual está llamada a satisfacer sus necesidades materiales, afectivas y psicológicas. Corte IDH. Condición Jurídica y Derechos Humanos del Niño. Opinión Consultiva OC-17/02 de 28 de agosto de 2002. Serie A No. 17, párrs. 67 y 71.

10 MINYERSKY, Nelly. "El niño como sujeto de derecho". En: Universidad de Buenos Aires. Hacia el Plan Fénix, diagnóstico y propuestas. Una estrategia de reconstrucción de la economía argentina para el crecimiento con equidad. Buenos Aires: Facultad de Ciencias Económicas de la Universidad de Buenos Aires, 2001.

11 De acuerdo con la Dra. Mónica González Contró: "hasta antes de la firma de la Convención y su posterior ratificación por parte de los Estados latinoamericanos, el tratamiento jurídico a las personas durante la minoría de edad estuvo basado en la 'doctrina de la situación irregular'”. GONZÁLEZ CONTRÓ, Mónica. "¿Menores o niñas, niños y adolescentes? Reflexiones en el contexto del debate en América Latina". En: PÉREZ CONTRERAS, María de Montserrat y MACÍAS VÁZQUEZ, María del Carmen. Marco teórico conceptual sobre menores versus niñas, niños y adolescentes. México: Instituto de Investigaciones Jurídicas de la Universidad Nacional Autónoma de México, Serie Memorias, No. 5, 2011 , p. 40. 
la niñez y obligando a renovar el enfoque de trabajo de las diversas instancias de regulación así como la redefinición de funciones tanto del Estado como del movimiento social ${ }^{12}$.

La identificación de la minoría de edad con la carencia de autonomía de voluntad e independencia individual han sido postulados tutelares que se han afianzado con rigor en las normas del derecho positivo, y que constantemente entran en conflicto con esquemas como el de la autonomía progresiva de niñas y niños establecido en el artículo 12 de la $\mathrm{CDN}^{13}$. Este último reconoce el desarrollo continuo de sus habilidades y establece la necesidad de ir concediendo capacidad en el ejercicio autónomo de sus derechos ${ }^{14}$.

\subsection{Tener presente una concepción amplia del principio de igualdad sustancial}

A nuestro juicio, la construcción de una perspectiva de infancia debe partir del reconocimiento de la diferencia como sustento mismo de la igualdad ${ }^{15}$. La Corte Interamericana ha señalado que las medidas de especial protección relacionadas con niñas y niños "adquieren fundamental importancia debido a que se encuentran en una etapa crucial de su desarrollo físico, mental, espiritual, moral, psicológico y social que impactará de alguna forma su proyecto de vida"16.

Tomando en consideración los factores estructurales que históricamente han sido un obstáculo para el pleno desarrollo de niñas y niños, es que el reconocimiento de una concepción amplia del principio de igualdad constituye uno de los elementos fundamentales que deben sustentar los derechos de las niñas y niños.

\subsection{Asegurar una plena eficacia del principio de interés superior de la niña y el niño}

Se ha dicho que para poder asegurar que las niñas y niños puedan tener una "vivencia social de los principios de efectividad, prioridad absoluta e interés superior se requiere sin duda de su vigencia en la estructura política del Estado, entendiendo que estos principios son orientadores para la refundación del mismo"17. El principio del interés superior (ISN) constituye una formulación paradigmática de las obligaciones del Estado en relación con niñas y niños que advierte la necesidad de reconocer la integralidad y satisfacción de los derechos enunciados en su favor.

12 GARCÍA MÉNDEZ, Emilio y CARRANZA, Elías. "El Derecho de 'Menores' como Derecho Mayor". En: GARCÍA MÉNDEZ, Emilio y CARRANZA, Elías (Orgs.). Del Revés al Derecho: la condición jurídica de la infancia en América Latina. Bases para una reforma legislativa. Buenos Aires: UNICEF, 1992.

13 El artículo 12 de la Convención sobre los Derechos del Niño refiere que: 1. Los Estados Partes garantizarán al niño que esté en condiciones de formarse un juicio propio, el derecho de expresar su opinión libremente en todos los asuntos que afectan al niño, teniéndose debidamente en cuenta las opiniones del niño, en función de la edad y madurez del niño. 2. Con tal fin, se dará en particular al niño oportunidad de ser escuchado, en todo procedimiento judicial o administrativo que afecte al niño, ya sea directamente o por medio de un representante o de un órgano apropiado, en consonancia con las normas de procedimiento de la ley nacional.

14 GONZÁlEZ CONTRÓ, Mónica, “¿Menores o niñas, niños y adolescentes?”, op. cit., p. 43.

15 ORTEGA SORIANO, Ricardo. Los derechos de las niñas y los niños en el Derecho Internacional, con especial atención al Sistema Interamericano de Protección de los Derechos Humanos. México: Comisión Nacional de los Derechos Humanos, 2011, p. 14.

16 Corte IDH. Caso "Instituto de Reeducación del Menor" vs. Paraguay. Excepciones Preliminares, Fondo, Reparaciones y Costas. Sentencia de 2 de septiembre de 2004. Serie C No. 112, párr. 172.

17 TORRES ZÁRATE, Fermín y GARCÍA MARTÍNEZ, Francisco. "El interés superior del niño en la perspectiva del garantismo jurídico en México". Revista Alegatos Coyuntural, Universidad Autónoma Metropolitana, No. 65, enero-abril, México, 2007, p. 99. 
Aunado a estas características, el principio del ISN supone la obligación de las autoridades del Estado de asegurar una "debida diligencia frente a la prevención, protección y restitución de los derechos de la infancia"18 que supondría, al menos, las siguientes características: (i) obligación de actuar bajo un marco específico de derechos; (ii) obligación de atender los derechos del niño de manera integral; (iii) el carácter reforzado de las obligaciones; (iv) obligación de aplicar el principio "pro niño" en temas que afectan a la infancia"

De esta manera, el principio del ISN deberá tomarse siempre en aquella medida que asegure la máxima satisfacción y menor restricción de los derechos; esto, no sólo considerando el número de derechos afectados, sino que también su importancia relativa ${ }^{20}$. Sin embargo, es importante señalar que el ISN no es absoluto, pues para su aplicación debe haber una ponderación adecuada entre los derechos de un niño/a y los derechos de otra persona y, como resultado de eso, en algunos casos concretos, la aplicación de este principio tiene que ser limitada, desde luego en el marco de las consideraciones hasta aquí expuestas ${ }^{21}$.

\subsection{Reconocer que ciertas afectaciones a derechos tienen un especial impacto en los derechos de niñas y niños, situación que exige obligaciones reforzadas a cargo del Estado}

El Estado debe asumir una posición especial de garante, tomando medidas especiales orientadas en el principio del ISN ${ }^{22}$ y prestar especial atención a las necesidades de niñas y niños en consideración a su condición particular de vulnerabilidad ${ }^{23}$.

El establecimiento de estas medidas especiales tendrían, por una parte, la finalidad de asegurar el respeto, protección y garantía de un abanico de derechos específicos a favor de niñas y niños, que se han instituido para hacer frente a la situación de especial vulnerabilidad; y, por la otra, evitar que se generen afectaciones en función de la especial magnitud que las mismas tienen en la esfera de niñas y niños ${ }^{24}$.

Con la finalidad de ejemplificar lo anterior, se presentarán algunos de los impactos diferenciados en perjuicio de los derechos de niñas y niños que se han identificado cuando se vulnera el plazo razonable en procedimientos judiciales donde participan.

18 Corte IDH. Caso Forneron e hija, op. cit., párr.78.

19 GRIESBACH GUIZAR, Margarita y ORTEGA SORIANO, Ricardo. El Estado frente al niño víctima del delito. Elementos para garantizar el efecto útil del interés superior del niño. México: INACIPE , 2013, p. 24.

20 TORRES ZÁRATE, Fermín y GARCÍA MARTíNEZ, Francisco. "El interés superior del niño...", op. cit., pp. $109-110$.

21 PRADILLA-RIVERA, Silvia. "Aplicación del principio del interés superior del niño(a) como mecanismo para proteger el derecho de los niños y las niñas a tener una familia y a no ser separados de ella". Revista Estudios Socio-Jurídicos, 2011, No. 13(1), pp. 329-348.

22 Corte IDH. Condición Jurídica y Derechos Humanos del Niño, op. cit., párr. 164.

23 Corte IDH. Caso Masacres de Río Negro vs. Guatemala. Excepción Preliminar, Fondo, Reparaciones y Costas. Sentencia de 4 de septiembre de 2012 Serie C No. 250, párr.142; Caso De la Masacre de las dos Erres vs. Guatemala. Excepción Preliminar, Fondo, Reparaciones y Costas. Sentencia de 24 de noviembre de 2009. Serie C No. 21, párr. 184; y, Caso Rosendo Cantú y otra vs. México. Excepción Preliminar, Fondo, Reparaciones y Costas. Sentencia de 31 de agosto de 2010. Serie C No. 216, párr. 201.

24 Corte IDH. Caso Furlán y Familiares vs. Argentina. Excepciones Preliminares, Fondo, Reparaciones y Costas. Sentencia de 31 de agosto de 2012 Serie C No. 246, párr.134; Caso de la "Masacre de Mapiripán" vs. Colombia. Fondo, Reparaciones y Costas. Sentencia de 15 de septiembre de 2005. Serie C No. 134, párrs. 111 y 113; y, Caso Pueblo Indígena Kichwa de Sarayaku vs. Ecuador. Fondo y reparaciones. Sentencia de 27 de junio de 2012. Serie C No. 245, párr. 244. 


\section{Los derechos humanos de niñas y niños que participan en procedimientos administrativos y judiciales}

Se ha sostenido que "las garantías judiciales y las reglas del debido proceso son de observancia obligatoria, por lo que deben aplicarse no sólo a los procesos judiciales, sino a cualesquiera otros procesos que siga el Estado" 25 .

La Corte IDH ha señalado que "las garantías consagradas en el artículo 8 de la Convención se reconocen a todas las personas por igual, y deben correlacionarse con los derechos específicos que estatuye, de tal forma que se reflejen en cualesquiera procesos administrativos o judiciales en los que se discuta algún derecho de un niño" 26 .

Así las cosas, es importante no perder de vista dos elementos relacionados con los derechos de niñas y niños que participan en procedimientos judiciales: por una parte, debe reconocerse la especial vulnerabilidad en la que se encuentran frente a un proceso legal, ya sea administrativo o judicial y, por la otra, tener presente el carácter fundamental que reviste contar con un sistema jurídico que descanse sobre una base amplia de igualdad que reconozca la integralidad de sus derechos.

\subsection{La situación de especial vulnerabilidad de niñas y niños que participan en un proceso judicial}

En primer término, es preciso recordar que "las condiciones en las que participa un niño en un proceso no son las mismas en que lo hace un adulto". Sostener otra consideración al respecto "desconocería la realidad y omitiría la adopción de medidas especiales para la protección de los niños" 27 .

Asimismo, es importante considerar las características de niñas y niños que resultan relevantes para su participación en un proceso judicial, a saber: (i) el desarrollo cognitivo que incide en el razonamiento abstracto y en las nociones del tiempo y espacio que afectan la narrativa infantil; (ii) el desarrollo emocional y los mecanismos inconscientes de defensa que modifican la conducta y el pensamiento infantil; (iii) el desarrollo moral, que incide en la manera en que responden frente a la necesidad de evitar el castigo, y su percepción de lo que es correcto ${ }^{28}$.

Estas características atienden a condiciones estructurales en niñas y niños, por lo que no son "modificables a través de la voluntad o el trato; son simplemente la manera en que funcionan a nivel emocional y cognitivo" 29 .

\subsection{La importancia de asegurar que un sistema jurídico descanse sobre una base amplia de igualdad sustancial}

En términos particulares, el principio de igualdad debe incorporar por lo menos los siguientes aspectos en los procesos administrativos y judiciales en donde participen niñas y niños:

\footnotetext{
25 Corte IDH. Condición Jurídica y Derechos Humanos del Niño, op. cit., párrs. 115 y 117.

26 Ibídem, párr. 95.

27 Ibídem, párr. 96.

28 Suprema Corte de Justicia de la Nación. Protocolo de actuación para quienes imparten justicia en casos que afecten a niñas, niños y adolescentes. 2a edición. México: Suprema Corte de Justicia, 2012, pp. 14 y 15.

29 Ibídem, p. 15.
} 
(i) Mecanismos que les permitan la mayor comprensión de los procedimientos en donde participan

La naturaleza misma de los procesos judiciales, la lógica en que están construidos, así como el desarrollo técnico de éstos, los hacen difíciles de comprender para todas aquellas personas ajenas al entorno jurídico. Esto puede agravarse si se analiza lo extraño que podría resultar un proceso judicial para una niña o niño así como el impacto del mismo, teniendo en cuenta el grado de su desarrollo cognitivo y emocional.

La Corte Interamericana ha señalado que no puede asegurarse el principio del ISN si no se reconoce el derecho que tienen a participar y ser escuchados en los procesos judiciales en donde intervienen ${ }^{30}$. Por ejemplo, en el Caso Atala Riffo e hijas vs. Chile, sostuvo que "Ios niños y niñas ejercen sus derechos de manera progresiva a medida que desarrollan un mayor nivel de autonomía personal", situación por la que dicho tribunal tuvo en consideración las edades de las niñas involucradas, ya que "podrían existir diferencias en sus opiniones y en el nivel de autonomía personal para el ejercicio de los derechos de cada una"31.

El propio tribunal, siguiendo el análisis realizado por el Comité de los Derechos del Niño de Naciones Unidas, sostuvo una serie de especificaciones que debían tenerse en consideración cuando se analizara el derecho de niñas y niños a ser escuchados en un proceso judicial o administrativo, en donde se resaltó que:

a) No puede partirse de la premisa de que niñas y niños son incapaces para expresar sus propias opiniones;

b) No es necesario que tengan un conocimiento exhaustivo del proceso, sino una comprensión suficiente para ser capaces de formarse adecuadamente un juicio propio sobre el asunto;

c) Las niñas y los niños deben poder expresar sus opiniones sin presión y escoger si quieren o no ejercer su derecho a ser escuchadas o escuchados;

d) Las y los responsables de escuchar a niñas y niños así como padres, madres y tutores deben informarles de los asuntos, las opciones y las posibles decisiones que pueden adoptarse y sus consecuencias;

e) Los niveles de comprensión no van ligados de manera uniforme a su edad biológica, por lo que la madurez de niñas y niños debe medirse a partir de la capacidad para expresar sus opiniones sobre las cuestiones de forma razonable e independiente ${ }^{32}$.

(ii) Autoridades especializadas que sean sensibles y comprensivas de la situación en que participan niñas y niños

La Corte Interamericana ha reconocido la exigencia de "atender en forma diferenciada y específica las cuestiones referentes a los niños" ${ }^{\prime 3}$, aspecto que revela la necesidad de que en aquellos procesos en donde participen, existan personas capaces de asegurar ese trato diferenciado y profesional que requiere de atención específica a niñas y niños, toda vez que "no basta con disponer protecciones

30 Corte IDH. Caso Atala Riffo y Niñas, op. cit., párr. 197.

31 Ibídem, párr. 68.

32 Ibídem, párr. 198. Retomando lo establecido por: Comité de los Derechos del Niño. El derecho del niño a ser escuchado. Observación General No. 12. CRC/C/GC/12, 20 de julio de 2009, párrs. 20, 21, 25, 28 y 30.

33 "[P]articularmente, las relacionadas con la conducta ilícita, es el establecimiento de órganos jurisdiccionales especializados para el conocimiento de conductas penalmente típicas atribuidas a aquéllos y un procedimiento especial por el cual se conozcan estas infracciones a la ley penal". Corte IDH. Condición Jurídica y Derechos Humanos del Niño, op. cit., párrs. 95 y 109. 
y garantías judiciales si los operadores del proceso carecen de capacitación suficiente sobre el interés superior del niño y sobre la protección efectiva de sus derechos" ${ }^{\prime 34}$.

(iii) Adecuación de procedimientos que tengan como eje fundamental el interés superior de la niña y el niño

Una de las consideraciones fundamentales para proteger los derechos de niñas y niños se relaciona con la necesidad de contar con procesos judiciales que tengan la suficiente "plasticidad" para amoldarse a sus necesidades y garantizar la materialización del ISN.

Por ello, para efectuar una correcta aplicación de dicho principio "debe atenderse tanto a consideraciones fácticas, las cuales corresponden a las circunstancias específicas del caso visto en su totalidad, así como a consideraciones jurídicas, como los parámetros y criterios establecidos por el ordenamiento jurídico para promover el bienestar infantil a fin de llegar a una solución respetuosa de su interés superior ${ }^{\prime \prime} 35$.

En este sentido, las autoridades encargadas de velar por el principio del ISN en procesos judiciales deberían tener la posibilidad de realizar un ajuste razonable a los procedimientos, a partir de los siguientes principios que, a nuestro juicio, son fundamentales para asegurar la aplicación del mismo ${ }^{36}$ :

a) Evitar la revictimización de niñas y niños. Los niños y niñas son el segmento de la población más altamente victimizado, sufren de los mismos crímenes y violencia que los adultos, y además muchas victimizaciones propias de la niñez ${ }^{37}$. La "revictimización" o "victimización secundaria" se da cuando a los efectos de la violación a derechos original, se le suman aqueIlos provocados por las experiencias a las que se enfrentan una vez que se inicia el proceso legal ${ }^{38}$. La Corte Interamericana ha sostenido que el hecho de que una autoridad judicial no tenga que recabar nuevamente el testimonio de un niño o niña, no la libera de la obligación de tener debidamente en cuenta y valorar las opiniones expresadas por la niña y el niño en las instancias inferiores, en función de su edad y capacidad ${ }^{39}$.

b) Asegurar la adopción de medidas especiales de protección ante situaciones de riesgo. Es importante tener presente la importancia de que las autoridades actúen de manera diligente frente a la presencia de "daños o riesgos reales y probados, y no especulativos o imaginarios" 40 . De acuerdo con la Corte IDH, no pueden ser admisibles especulaciones, presunciones, estereotipos o consideraciones generalizadas sobre características personales de los padres o preferencias culturales respecto de ciertos conceptos tradicionales de la familia ${ }^{41}$. Sin embargo, no debe

34 Ibídem, párrs. 79 y 95.

35 PRADILLA-RIVERA, Silvia. "Aplicación del principio del interés superior del niño(a)...", op. cit., pp. 329-348.

36 En este punto, se retoman los dos elementos que se han destacado para asegurar el efecto útil del principio ISN, y que consisten esencialmente en: a) obligación de brindar un trato diferenciado y especializado; y b) obligación de atender de manera reforzada e integral toda afectación a los derechos del niño aplicando el principio "pro niña-niño". GRIESBACH GUIZAR, Margarita y ORTEGA SORIANO, Ricardo Alberto. El Estado frente al niño víctima del delito, op. cit., p. 24.

37 Oficina de Defensoría de los Derechos de la Infancia. "El Niño Víctima del Delito. Fundamentos y Orientaciones para una Reforma Procesal Penal". En: El Niño Víctima del Delito Frente al Proceso Penal. Tomo I. México: Oficina de Defensoría de los Derechos de la infancia, 2009, pp. 33-36.

38 Ídem.

39 Corte IDH. Caso Atala Riffo, op. cit., párr. 206.

40 Ibídem, párr. 109.

41 La Corte Interamericana utiliza los siguientes elementos para ejemplificar esta situación: "[E]n Australia: In the Marriage of C. and J.A. Doyle, (1992) 15 Fam. L.R. 274, 274, 277 ('el estilo de vida de los progenitores no es relevante sin considerar sus consecuencias en el bienestar del niño'); en las Filipinas: Corte Suprema de las Filipinas, Joycelyn Pablo-Gualberto 
perderse de vista la necesidad de que las autoridades también asuman frente a la existencia de alguna duda razonable sobre la posible afectación a los derechos de niñas y niños y, en particular, en lo relativo a su vida e integridad, el principio "protección- precaución", que consiste en asegurar la máxima diligencia frente al riesgo que derive de tal análisis de racionalidad.

\section{El demoledor peso del tiempo frente a los derechos de niñas y niños y las graves afectaciones derivadas de la ausencia de una debida diligencia en asuntos que afectan sus derechos}

Una vez que se ha explicitado el marco de referencia de un enfoque o perspectiva de infancia en términos generales y luego frente a procedimientos judiciales o administrativos, se ejemplificarán las afectaciones especialmente graves en los derechos de niñas y niños que produce la falta de un plazo razonable; las que pueden ser mayormente comprendidas a la luz del marco teórico hasta aquí desarrollado.

\subsection{Plazo razonable: el estándar general de la Corte Interamericana de Derechos Humanos}

El derecho de acceso a la justicia exige la determinación de los derechos de la persona en un tiempo razonable; la falta de razonabilidad en el plazo constituye, por sí misma, una violación de las garantías judiciales ${ }^{42}$.

En este sentido, para el principio de celeridad procesal reviste importancia capital el concepto de plazo razonable, que se aplica a la solución jurisdiccional de una controversia e implica que haya razonabilidad en el trámite y conclusión de las diversas etapas del procedimiento que llevarán a la sentencia definitiva ${ }^{43}$.

En el sistema interamericano, los artículos 7.5 y 8.1 de la Convención Americana contemplan, por lo menos, dos contextos en los que se hace imperiosa la observancia del plazo razonable. El primero, tendiente a la protección del derecho a la libertad personal y el segundo en el marco de las garantías judiciales y el debido proceso $^{44}$.

El propio tribunal interamericano ha reiterado una serie de elementos a considerarse en el concepto de plazo razonable: “a) complejidad del asunto; b) actividad procesal del interesado;

v. Crisanto Rafaelito Gualberto, G.R. No. 156254 de 28 de junio de 2005, señalando que la preferencia sexual en sí misma no es muestra de la incompetencia parental de ejercer la custodia de menores ('sexual preference or moral laxity alone does not prove parental neglect or incompetence. [...] To deprive the wife of custody, the husband must clearly establish that her moral lapses have had an adverse effect on the welfare of the child or have distracted the offending spouse from exercising proper parental care'); en Sudáfrica: Corte Constitucional de Sudáfrica, Du Toit and Another v Minister of Welfare and Population Development and Others (CCT40/01) [2002] ZACC 20; 2002 (10) BCLR 1006; 2003

(2) SA 198 (CC) (10 September 2002), permitiendo la adopción de menores de edad por parejas del mismo sexo por considerar que no afectará el interés superior del niño, y Corte Constitucional de Sudáfrica, J and Another v Director General, Department of Home Affairs and Others (CCT46/02) [2003] ZACC 3; 2003 (5) BCLR 463; 2003 (5) SA 621 (CC) (28 March 2003)". Ídem.

42 Corte IDH. Caso Forneron e hija, op. cit., párr. 66; Caso Hilaire, Constantine y Benjamin y otros vs. Trinidad y Tobago. Fondo, Reparaciones y Costas. Sentencia de 21 de junio de 2002. Serie C No. 94, párr. 145; y, Caso González Medina y familiares vs. República Dominicana. Excepciones Preliminares, Fondo, Reparaciones y Costas. Sentencia de 27 de febrero de 2012. Serie C No. 240, párr. 257.

43 GARCÍA RAMÍREZ, Sergio. Los derechos humanos y la jurisdicción interamericana. México: Instituto de Investigaciones Jurídicas, Serie Doctrina Jurídica. No. 106, 2002, pp. 133-134.

44 RODRÍGUEZ BEJARANO, Carolina. "El plazo razonable en el marco de las garantías judiciales en Colombia". En: Aportes de la jurisprudencia de la Corte Interamericana a la Consolidación del Sistema Regional de Protección. Colombia: Adscrita al Grupo de Investigación en Derechos Humanos reconocido por la Universidad Libre-Seccional Pereira, 2011, p. 114. 
c) conducta de las autoridades judiciales, y d) afectación generada en la situación jurídica de la persona involucrada" 45 .

Tales elementos han sido desarrollados por la propia Corte, estableciendo que para considerar la complejidad de un asunto debe observarse "la complejidad de la prueba, la pluralidad de sujetos o víctimas, el tiempo transcurrido desde la violación, las características del recurso y el contexto en el que ocurrió la violación" ${ }^{46}$.

Por otra parte, de acuerdo con dicho tribunal, "la actuación de la parte interesada se centra principalmente en: (i) el tiempo transcurrido para la determinación de la parte demandada, y (ii) el impulso procesal efectuado por la presunta víctima en otras etapas del proceso" ${ }^{\prime 4}$. Asimismo, ha referido que "no es posible alegar obstáculos internos, tales como la falta de infraestructura para eximirse de una obligación internacional y que una sobrecarga crónica de casos pendientes no es una justificación válida del retraso excesivo" ${ }^{48}$.

Finalmente, y en relación con el último de los elementos, la Corte ha reconocido que debe tomarse en cuenta la afectación generada por la duración del procedimiento en la situación jurídica de la persona involucrada, considerando, entre otros elementos, la materia objeto de controversia, y si el paso del tiempo incide de manera relevante en la situación jurídica del individuo, resultará necesario que el procedimiento avance con mayor diligencia a fin de que el caso se resuelva en un tiempo breve ${ }^{49}$.

\subsection{La construcción de un estándar reforzado de protección aplicado a la concepción del plazo razonable en procedimientos legales en donde intervienen niñas y niños}

Es importante resaltar que el estándar general del plazo razonable tendría que ser comprendido a la luz de las graves afectaciones que su vulneración puede tener en los derechos de niñas y niños. Es decir, el estándar general relativo a recibir justicia en un plazo razonable se torna insuficiente para la protección de los derechos de niñas y niños si no se adoptan medidas especiales y reforzadas que eviten una afectación particularmente nociva para sus derechos.

La Corte Interamericana ha sostenido que los procedimientos administrativos y judiciales concernientes a la protección de los derechos de personas menores de edad, particularmente aquellos procesos judiciales relacionados con la adopción, la guarda y la custodia de niños y niñas, deben ser manejados con una diligencia y celeridad excepcionales por parte de las autoridades ${ }^{50}$.

Particularmente, en el caso Fornerón vs. Argentina, la Corte estableció que,

[E]I mero transcurso del tiempo en casos de custodia de menores de edad puede constituir un factor que favorece la creación de lazos con la familia acogedora. Por ende, la mayor dilación en los procedimientos, podía determinar el carácter irreversible de la situación de hecho y volver perjudicial para los intereses de niños y padres biológicos, cualquier decisión al respecto ${ }^{51}$.

\footnotetext{
45 Corte IDH. Caso Forneron e hija, op. cit., párr. 66.

46 Corte IDH. Caso Furlan y Familiares, op. cit., párr.156.

47 Ibídem, párr. 164.

48 Corte IDH. Caso Forneron e hija, op. cit., párr. 74.

49 Ibídem, párr. 75.

50 Ibídem, párr. 51; Corte IDH. Asunto L.M. Medidas Provisionales respecto de Paraguay. Resolución de 1 de julio de 2011 , considerando 16 .

51 Corte IDH. Caso Forneron e hija, op. cit. párr. 52.
} 
En efecto, la constatación de la Corte, respecto de las consideraciones irreversibles derivadas del mero transcurso del tiempo, obligaría a revisar la aplicación general del concepto de plazo razonable, ya que su aplicación en casos donde intervienen niñas y niños llevaría a una re lectura del mismo desde una perspectiva de infancia.

Esta circunstancia es advertida por la Corte IDH al manifestar que "la particularidad de este caso consistía en que el tiempo que estaba transcurriendo podía generar efectos irreparables en la situación jurídica del señor Fornerón y de su hija", pues las "autoridades no aceleraron el proceso a su cargo y no tuvieron en cuenta los efectos que el tiempo tendría sobre sus derechos, ello en consideración del ISN" ${ }^{52}$. Aunado a ello, a juicio de la propia Corte la afectación del plazo razonable generó vulneraciones adicionales a otros derechos, como el de protección de la familia y los derechos de la niña ${ }^{53}$.

La constatación de la Corte Interamericana ha sido en realidad la aplicación de un criterio reconocido por la Corte Europea de Derechos Humanos en diversos casos donde ha dicho que se tomó en consideración "lo que estaba en juego", "el carácter particular de irreversibilidad" y "las expectativas de vida de una persona" ${ }^{\prime 4}$.

\section{Conclusión}

El presente trabajo ha propuesto una aproximación a lo que hemos denominado enfoque o perspectiva de infancia. Los bosquejos que hasta ahora se han trazado de la misma nos permiten comprender de una manera integral y profunda el alcance de los derechos de niñas y niños.

Es claro que la construcción de una perspectiva como la que proponemos deberá ser revisada y repensada a partir de las crecientes formulaciones de la teoría de los derechos humanos en relación con sus categorías de análisis. No es el propósito de este estudio un afán de exhaustividad ni mucho menos concluir con tan titánica tarea. Sin embargo, la sola posibilidad de generar un marco de protección a los derechos de niñas y niños, identificar los obstáculos estructurales que enfrentan sus derechos, y reconstruir un número importante de categorías jurídicas que obstaculizan el desarrollo de los derechos de dichas personas, es razón suficiente para intentar comprender de manera integral esta circunstancia.

Recibido: 14 noviembre 2012

Aceptado: 30 enero 2013

52 Ibídem, párr. 70.

53 Ibídem, párr. 109.

54 La Corte Interamericana ha referido que "El Tribunal Europeo de Derechos Humanos, en reiteradas oportunidades ha utilizado este criterio en el análisis de plazo razonable. En efecto, en el caso $H$. v. Reino Unido, dicho Tribunal hizo especial énfasis en la importancia de 'lo que estaba en juego' para el accionante, y determinó que el resultado del procedimiento en cuestión tenía un carácter particular de irreversibilidad, por lo que en este tipo de casos las autoridades deben actuar con una diligencia excepcional. Asimismo, en el caso X. v. Francia, el Tribunal manifestó que las autoridades judiciales debían actuar de manera excepcionalmente diligente en un procedimiento en el que estaba involucrado una persona con SIDA, ya que lo que estaba en juego para el accionante era de crucial importancia, tomando en cuenta que sufría de una enfermedad incurable que reducía sus expectativas de vida. De igual forma, en los casos Codarcea v. Rumanía y Jablonska v. Polonia, el Tribunal Europeo consideró que la avanzada edad de los accionantes requería de una especial diligencia de las autoridades en la resolución del proceso". Corte IDH. Caso Furlan y Familiares, op. cit., párr. 195. 